\title{
Methods for Analyzing the Structure of Creases in Heat Sealed Paperboard Packages
}

\author{
Ville Leminen \\ Lappeenranta University of Technology \\ ville.1eminen@1ut.fi \\ Panu Tanninen \\ Lappeenranta University of Technology \\ panu.tanninen@lut.fi
}

\author{
Petri Mäkelä \\ Lappeenranta University of Technology \\ petri.makela@,1ut.fi \\ Juha Varis \\ Lappeenranta University of Technology \\ juha.varis@lut.fi
}

\begin{abstract}
Press-forming of paperboard has been previously studied by several authors. A point of interest regarding gas tight heat sealing of the packages are the creases in the package. The objective of this article was to study and compare different microscopic imaging methods to research an optimal imaging method for the formation of creases in the press-forming process of polymer coated paperboard trays. The studied methods were: Scanning electrode microscopy (SEM), X-ray Microtomography, Optical light microscopy and Polarized light microscopy. All four tested methods delivered clear images. Casting of the samples in an acrylic resin and light microscope imaging was found to be the most suitable method for the analysis of heat sealed creases and leakage detection.
\end{abstract}

Key Words: paperboard, press-forming, heat sealing, microscope, crease

\subsection{INTRODUCTION}

Three dimensional forming and material behavior of paperboard in the press forming process has been previously studied by several authors. [1] - [7] However, tray shaped, paperboard based and polymer coated packages have not yet been able to become a significant competitor to polymer based packages in food packaging when the use of modified atmosphere packaging (MAP) is required. This is mainly because the tightness of the packages especially in the area where the lid is heat sealed to the package has been a problem. A major cause for this are creases in the sealing area that are done to control and enable the formation of paperboard to certain geometries. [7],[8] The creases can act as capillary tubes that may cause leaks in the package when a lid is heat sealed to the tray. A poor sealing result can be a critical factor affecting shelf life of food. [9] Faults in sealing surface or other 
faults such as cracks or pinholes in the package can cause the MAP to leak from the package. Leakage of MAP can cause reduction in sensory shelf life and microbiological quality of packed foods [18].

There are several different methods for testing package and seal integrity. One common method is destructive dye penetrant testing that is usually done according to standards, such as European standard EN 13676 [14], ASTM F1929 [19] or ASTM F3039 [20]. Industrial practices include test methods such as using a leak detection system which forms a vacuum into a chamber and detects possible leaks. [21] One option is to use an Optical Fluorescence $\mathrm{O}_{2}$ Analyzer which utilizes standard ASTMF-2714-08 [22]. However, these methods do not provide insight to the exact mechanisms which cause the leaks. This kind of information can be achieved only by microscopic analysis.

This paper compares different microscopic imaging methods to research an optimal imaging method for the formation of creases in the pressforming process of polymer coated paperboard trays. The formation of creases is a critical investigation point when a gas tight heat seal is required in food packaging. The object was to find a cost effective and reliable method for the comparison of creases after press forming of polymer coated paperboard trays and after the heat sealing of a polymer based lidding film. Microscopic- and leakage analysis was done after heat sealing of a lidding film to the tray to investigate the visibility of said lidding film and leakage in the images. This kind of analysis is needed in order to get a better understanding of the formation of the creases and to improve the quality of trays produced in the press forming process

\subsection{MATERIALS}

The material used in the trays was Stora Enso Trayforma Performance $350+40$ WPET which is a polyethylene terephthalate (PET) extrusion-coated paperboard with a base material grammage of 350 $\mathrm{g} / \mathrm{m}^{2}$ and a coating grammage of $40 \mathrm{~g} / \mathrm{m}^{2}$. The base board consists of three solid bleached sulphate (SBS) layers. [10]

The materials were stored in a constant humidity chamber at $85 \%$ relative humidity to ensure sufficient humidity.

This higher humidity was used to maintain the delivery moisture content of the paperboard. The average humidity of the tested materials was measured using an analysis scale. The measured moisture content of the material was $10.2 \%$.

Elongation values for tested materials measured in $23{ }^{\circ} \mathrm{C}$ and $50 \% \mathrm{RH}$ was approximately $5 \%$ in cross direction and $2.5 \%$ in the machine direction. However according to [11], by varying the moisture and / or temperature of paper based materials, it is possible to get gains in elongation of around 2 to 2.5 percentage points, and therefore the elongation values in tray pressing can be higher.

The lidding material used in the heat sealing was a PET-sealable multi-layer film, Westpak WestTop 405B PET.

The material used in the sample preparation of light microscopy samples was Struers ClaroCit which is a clear and easily polished acrylic resin which is suitable to be used with paperboard and polymer materials because it hardens without the use of pressure or heat. [12]

\section{METHODS}

\subsection{PRESS-FORMING OF PAPERBOARD TRAYS}

Press-forming is a process which is used to create 


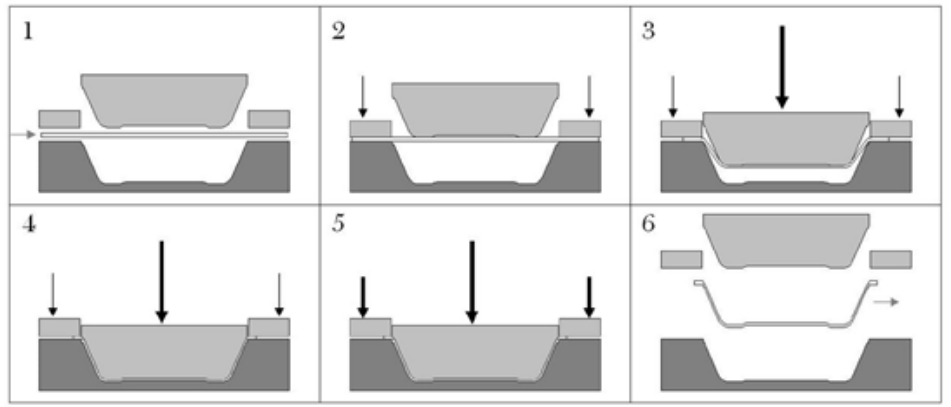

Figure 1: Tray-forming Process

three-dimensional shapes such as plates or trays. The tray forming process is presented in Figure 1.

Phase 1: The paperboard blank is positioned between the moulding tools.

Phase 2: The blank holding force tightens the blank between the rim tool and the female tool.

Phase 3: The male tool presses the blank into the mould cavity in the female tool. Folding of the tray corners is controlled with blank holding force.

Phase 4: The male tool is held at the bottom end of the stroke for a set time $(0.5$ to $1.0 \mathrm{~s})$. The plastic coating softens, and creases in the corners of the tray are sealed together.

Phase 5: The flange of the tray is flattened by the rim tool.

Phase 6: The formed tray is removed, and a new blank can be fed into the tray press. The tray achieves its final rigidity when it cools down.

Sample trays (example of tray geometry in Figure 2) were manufactured at the Laboratory of Packaging Technology at Lappeenranta University of Technology (LUT). The tray dimensions were $319 \times 216 \times 38 \mathrm{~mm}$. The formation of creases was analyzed using four different imaging methods to compare the suitability of these methods for this kind of analysis. The used press-forming parameters are presented in Table 1.

\begin{tabular}{|l|l|l|l|l|}
\hline $\begin{array}{l}\text { Female tool tempera- } \\
\text { ture }\end{array}$ & $\begin{array}{l}\text { Pressing dwell } \\
\text { time }\end{array}$ & Pressing force & Pressing speed & $\begin{array}{l}\text { Rim tool holding } \\
\text { force }\end{array}$ \\
\hline $170^{\circ} \mathrm{C}$ & $1 \mathrm{~s}$ & $135 \mathrm{kN}$ & $130 \mathrm{~mm} / \mathrm{s}$ & $1.16 \mathrm{kN}$ \\
\hline
\end{tabular}

Table 1. Forming parameters, rectangular tray 


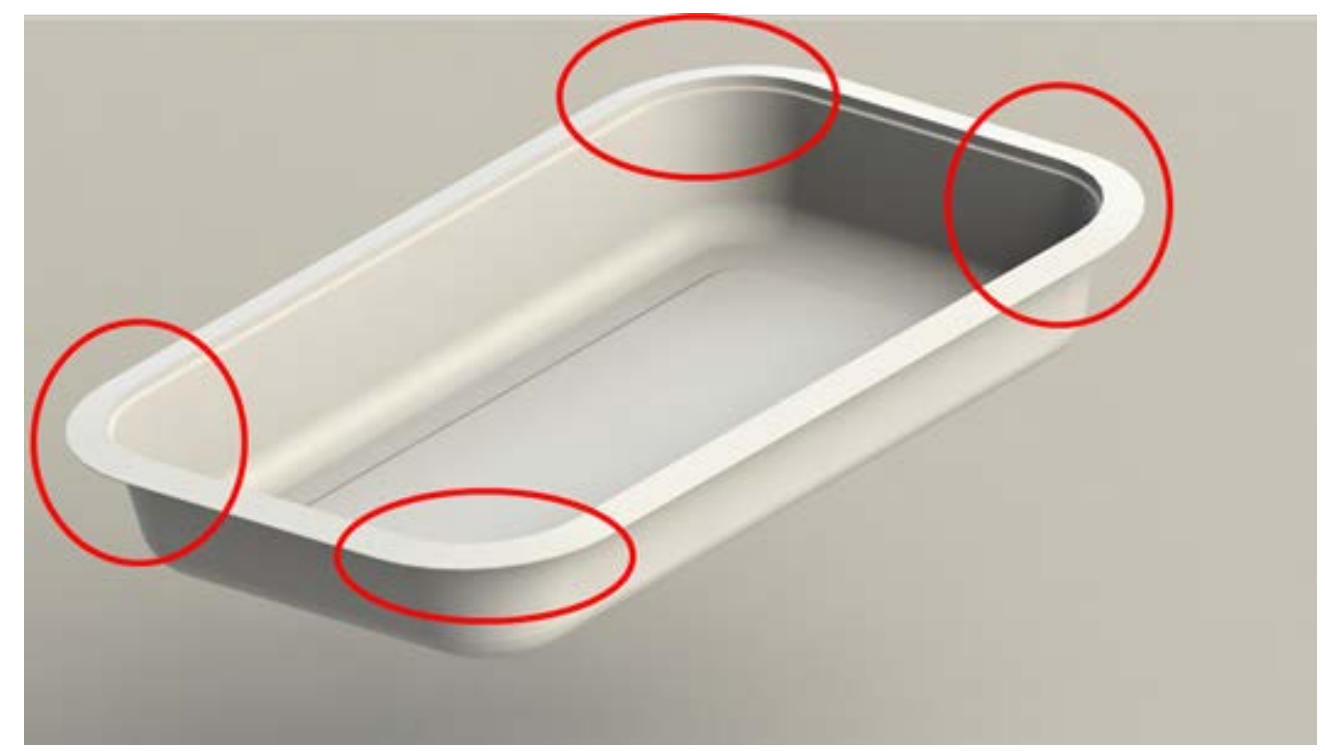

Figure 2. Tray geometry and areas where the inspected samples were extracted from (highlighted by red)

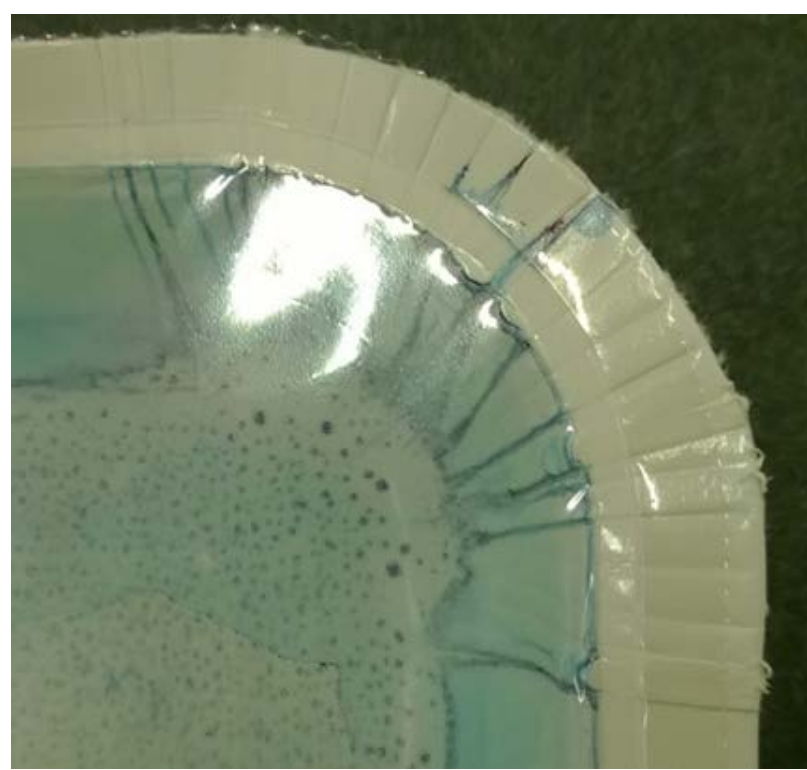

Figure 3. A leak in a tray corner indicated by a coloring solution

\subsection{HEAT SEALING AND LEAKAGE INVESTIGATION OF TRAYS}

The trays were heat sealed with a PET-sealable multi-layer film using an industrial scale heat sealing device. [13] The seals were tested with a coloring solution applying the European standard EN 13676. [14] The reagents in the coloring solution were dyestuff E131 Blue and Ethanol (C2H5OH, 96\%). The color solution consisted of $0.5 \mathrm{~g}$ dyestuff in $100 \mathrm{ml}$ ethanol. Possible leaks were located (Figure 3.) and after that the leak spot was investigated with different methods to compare the visibility of leaks in the images.

\subsection{MICROSCOPIC ANALYSIS METHODS}

The heat sealed trays were analyzed using four different imaging methods; scanning electron microscopy (SEM), X-ray microtomography, light microscopy and polarized light microscopy. All methods were tested extensively by analyzing leaking creases revealed by the coloring solution 
and also creases that were found to be sealed properly. Same samples were not analyzed with every method because the methods require specific sample preparation. In total over 200 trays were analyzed with dye penetrant testing. The amount of samples tested by each of the methods varied from 10 (X-ray microtomography and SEM) to 115 (Optical light microscopy).

Table 2. Number of tested samples by each method

\begin{tabular}{|c|c|}
\hline Method & $\begin{array}{c}\text { Number of tested } \\
\text { samples }\end{array}$ \\
\hline $\begin{array}{c}\text { Scanning electron } \\
\text { microscopy (SEM) }\end{array}$ & 10 \\
\hline $\begin{array}{c}\text { X-ray } \\
\text { Microtomography }\end{array}$ & 10 \\
\hline $\begin{array}{c}\text { Optical light } \\
\text { microscopy }\end{array}$ & 115 \\
\hline $\begin{array}{c}\text { Polarized light } \\
\text { microscopy }\end{array}$ & 14 \\
\hline
\end{tabular}

\subsubsection{SCANNING ELECTRON MICROSCOPY (SEM)}

Scanning electron microscopy uses focused electron beams to sweep the object and creates a very accurate image of the surface and its topography based on the scattering of the electrons. SEM-images have a nearly three dimensional effect and they make the understanding of the surface structure easier than purely 2D images. Magnification of SEM images varies from 10 times to 500000 times.

SEM-imaging requires that the surfaces that are studied have to be electrically conductive. This poses a problem with paperboard as samples have to be treated in order for them to conduct electricity. Most common surface treatment for SEM imaging is gold plating. SEM-imaging also requires nearly vacuum conditions, that may affect more delicate samples and it also consumes large amounts of power. [15]

\subsubsection{X-RAY MICROTOMOGRAPHY}

X-ray microtomography is an adaptation of the tomography method, which is widely used in medical science. It is based on absorption of $\mathrm{x}$-rays within the object that is being imaged. A typical microtomography device has a revolving $\mathrm{x}$-ray source that is opposed by $\mathrm{x}$-ray detectors, that measures the intensity of the radiation passing through the studied object. Process yields a series of projection images that can then be reconstructed into a complete 3D-model of the object of interest by using computer algorithms. [16]

The material preparation was done by cutting a small sample (Figure 4) and attaching it to a stand. The size of the sample is small and only one or two creases can be analyzed at a time.

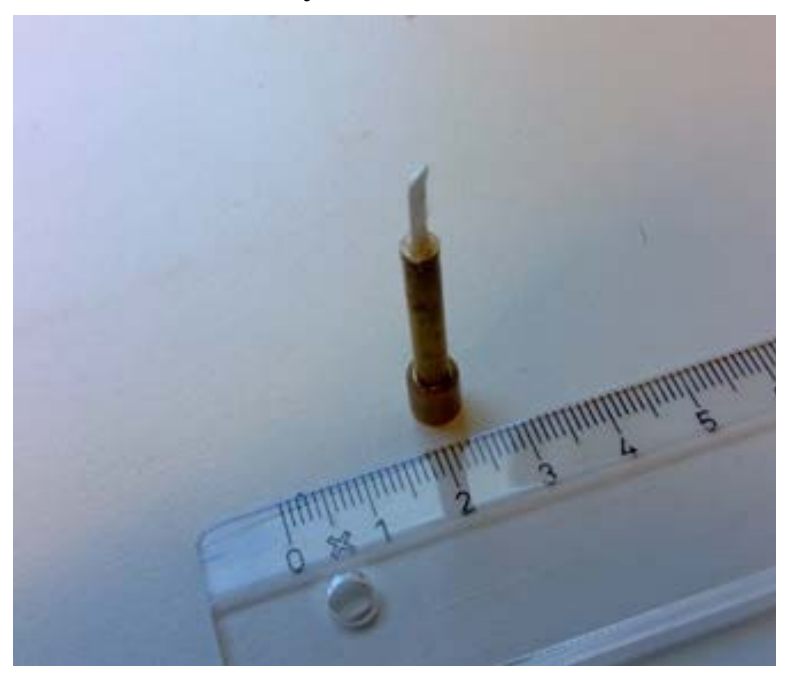

Figure 4. Prepared sample for X-ray microtomography. Scale numbering is in centimenters. 


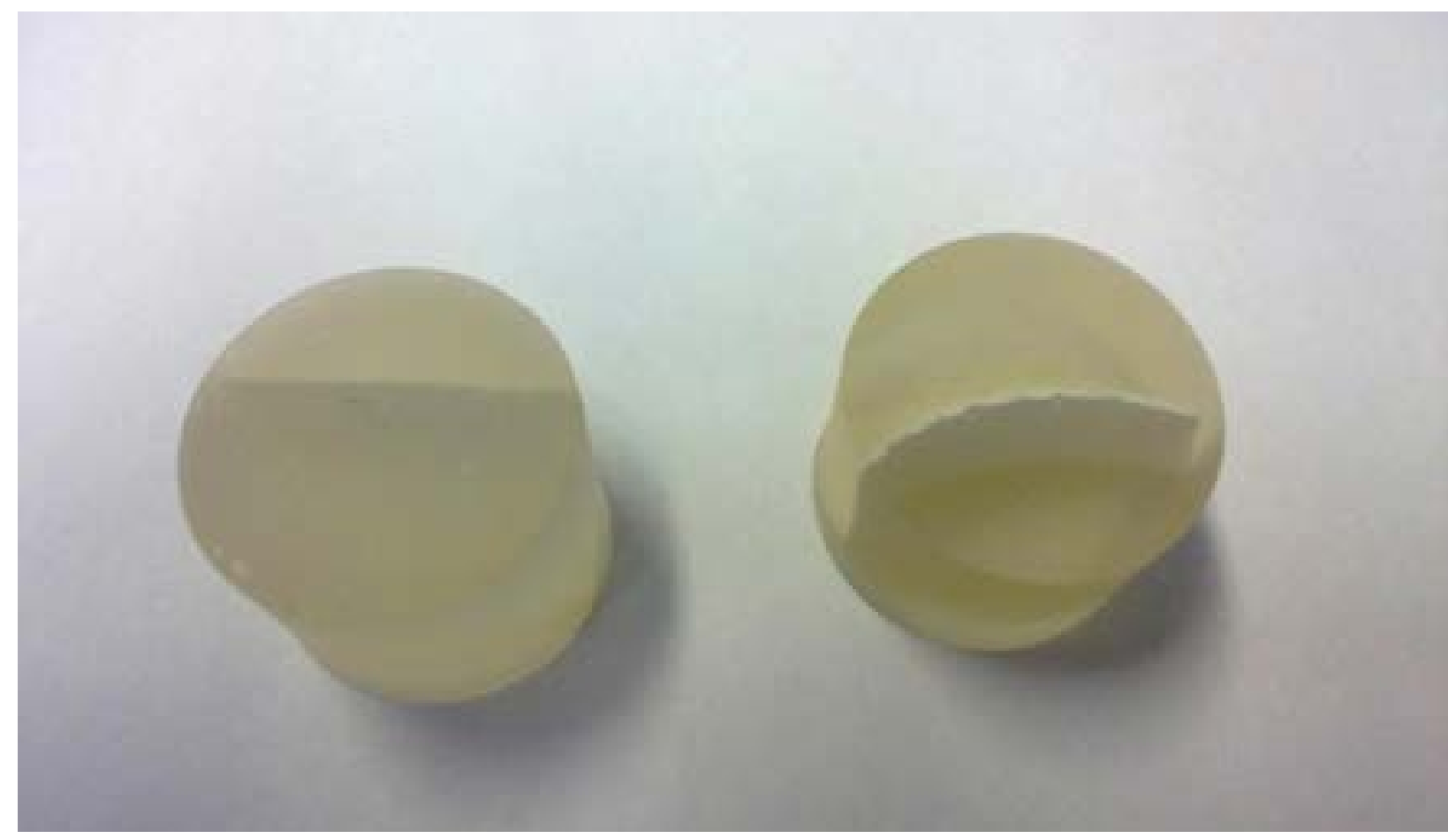

Figure 5. Prepared samples before (left) and after (right) polishing. The diameter of the samples is 30 $\mathrm{mm}$. One sample contains about 10 creases depending on tray geometry.

\subsubsection{OPTICAL LIGHT MICROSCOPY}

Light microscopy is the oldest tool in studying microstructure of materials. However, paperboard samples are difficult to study under a traditional microscope without proper sample preparation. A technology used normally to study metallurgical samples was applied into paperboard analysis.

In the method a cross-sectional paperboard sample is cut and then installed into a silicon mold. The mold is then filled with clear acrylic resin. After the resin hardens, the acrylic resin cast sample is removed from the mold. The cast sample is then polished with fine grit sandpapers and aluminum oxide solution, in a same manner as metallurgical samples are polished.

The finished sample (Figure 5) is studied and with a standard metallurgical microscope. The microscope is equipped with a digital camera that allows capturing images from the samples.

\subsubsection{POLARIZED LIGHT MICROSCOPY}

Polarized light microscopy is a technique involving polarized light. It can be done utilizing a number of optical microscopy methods. Polarized light microscopy can provide information on absorption color and optical path boundaries between different structures of materials. It can be used to identify different materials that are otherwise impossible to separate such as the layers in polymer films. [17]

\section{RESULTS AND DISCUSSION}

Extensive studies were conducted in order to compare different imaging systems for paperboard samples. Cross-sectional imaging methods were 
tested in general forming studies and in leak analysis. All four tested methods delivered clear images. However there were large differences in the usability of different methods.

\subsection{SCANNING ELECTRON MICROSCOPY (SEM)}

SEM images (example in Figure 6) offer great detail and show the different layers of materials clearly. It has far greater magnification and detail than other tested methods. The magnification of SEM allows investigating the formation in individual fibers of the paperboard. However, when analyzing the formation of a single crease and the sealing of the lidding film this kind of accuracy and magnification level is not required. Also, high cost of equipment, sample preparation and required gold plating of samples are drawbacks of using SEM.

\subsection{X-RAY MICROTOMOGRAPHY}

While X-ray microtomography offers insightful information of a single crease and it's deformation through the sealing surface, the lidding film is not clearly visible in the images (example in Figure 7). Lack of visibility of the sealing film makes it impossible to use X-ray microtomography in leak detection and analysis. The high equipment cost and challenging sample preparation are also significant shortcomings of microtomography.

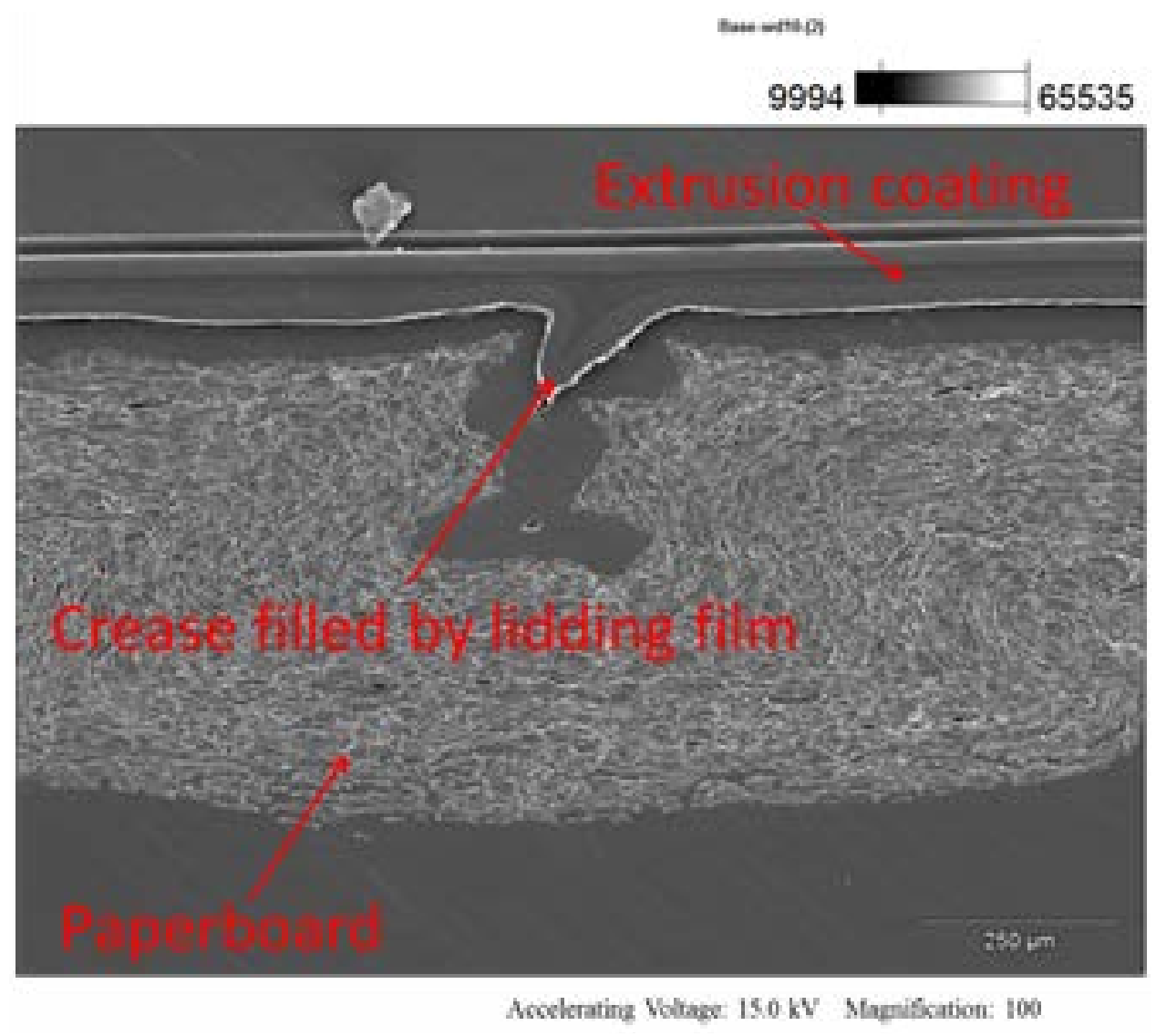

Figure 6. A SEM image 


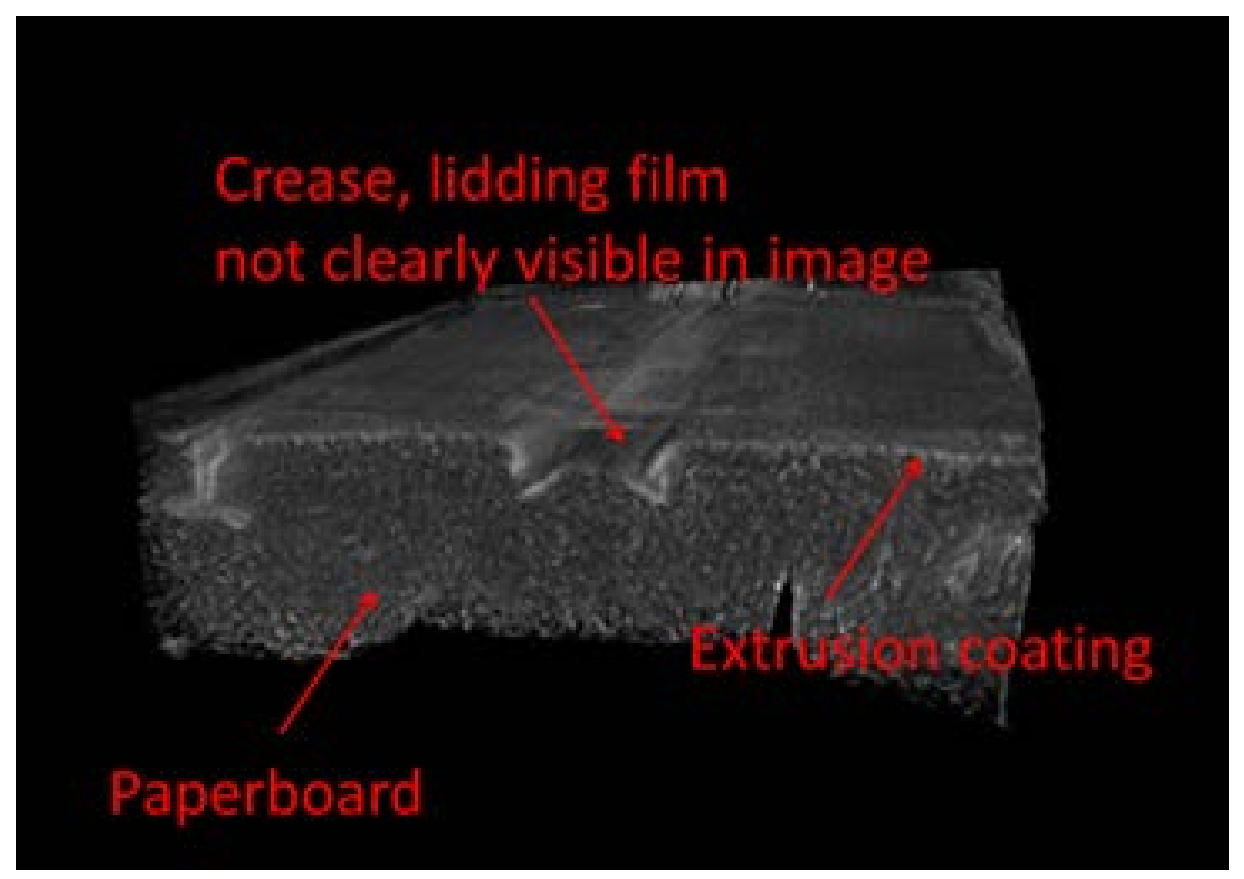

Figure 7. An X-ray microtomography image

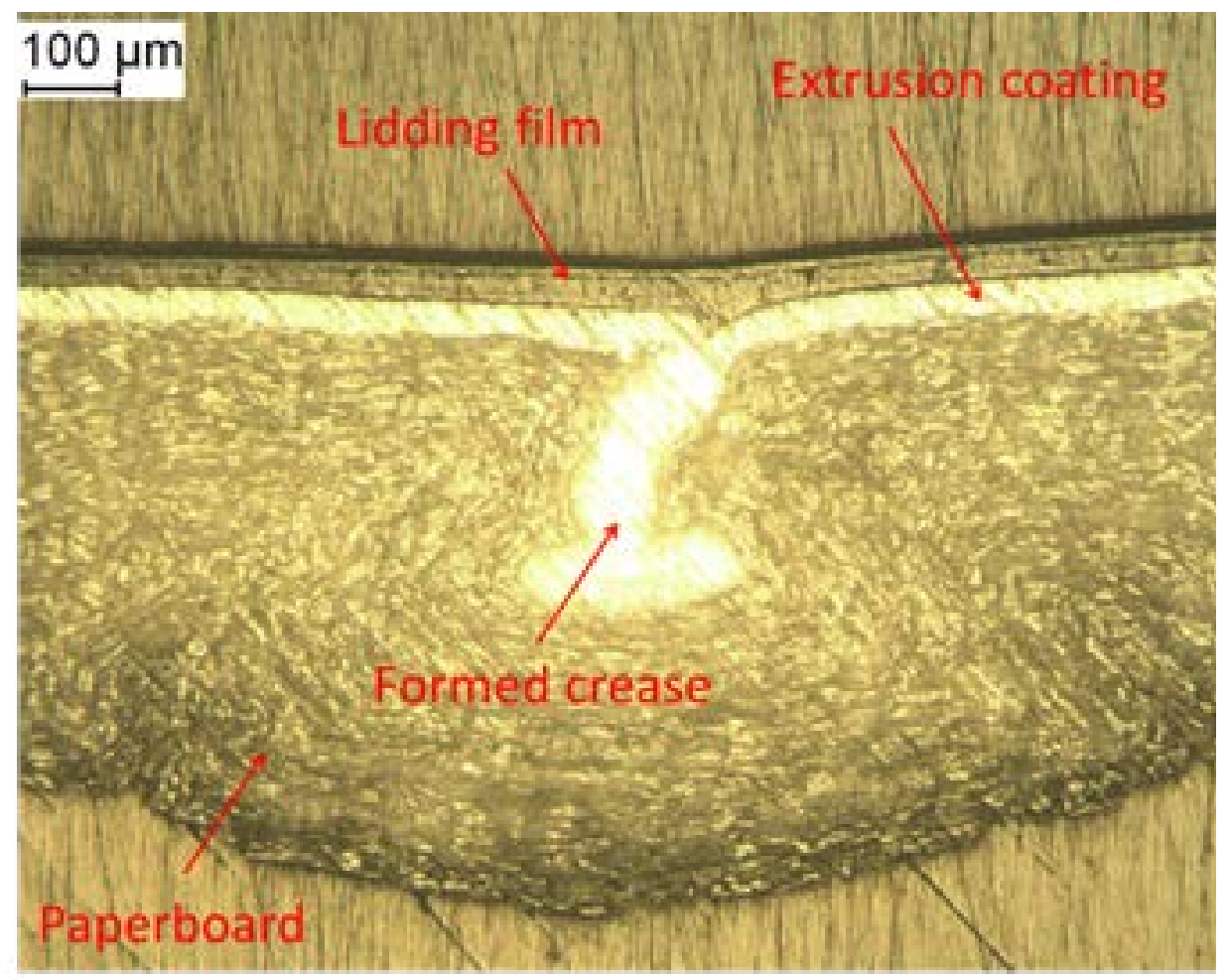

Figure 8. A microscopic image of a tight seal taken with an optical light microscope 


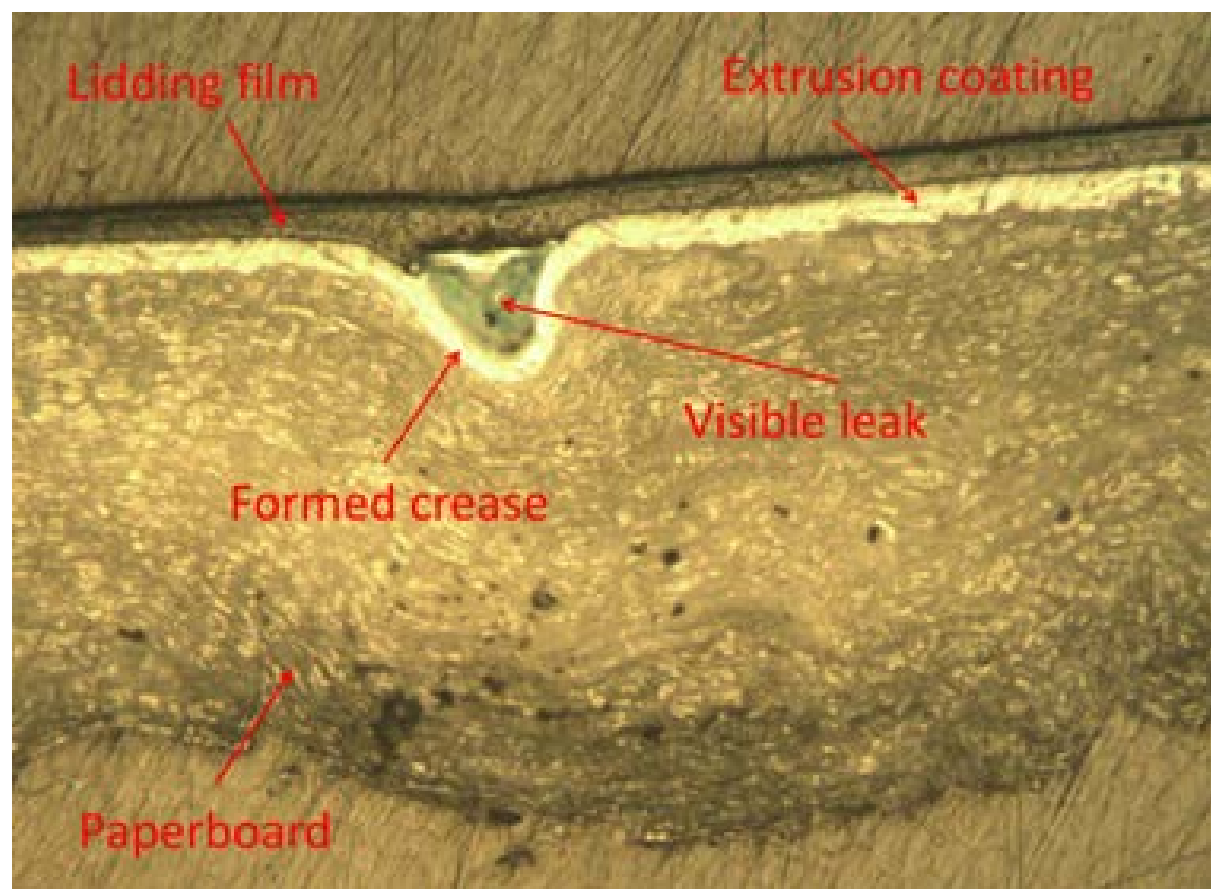

Figure 9. A microscopic image of a leaking seal taken with an optical light microscope. The coloring solution and a leaking crease is clearly visible

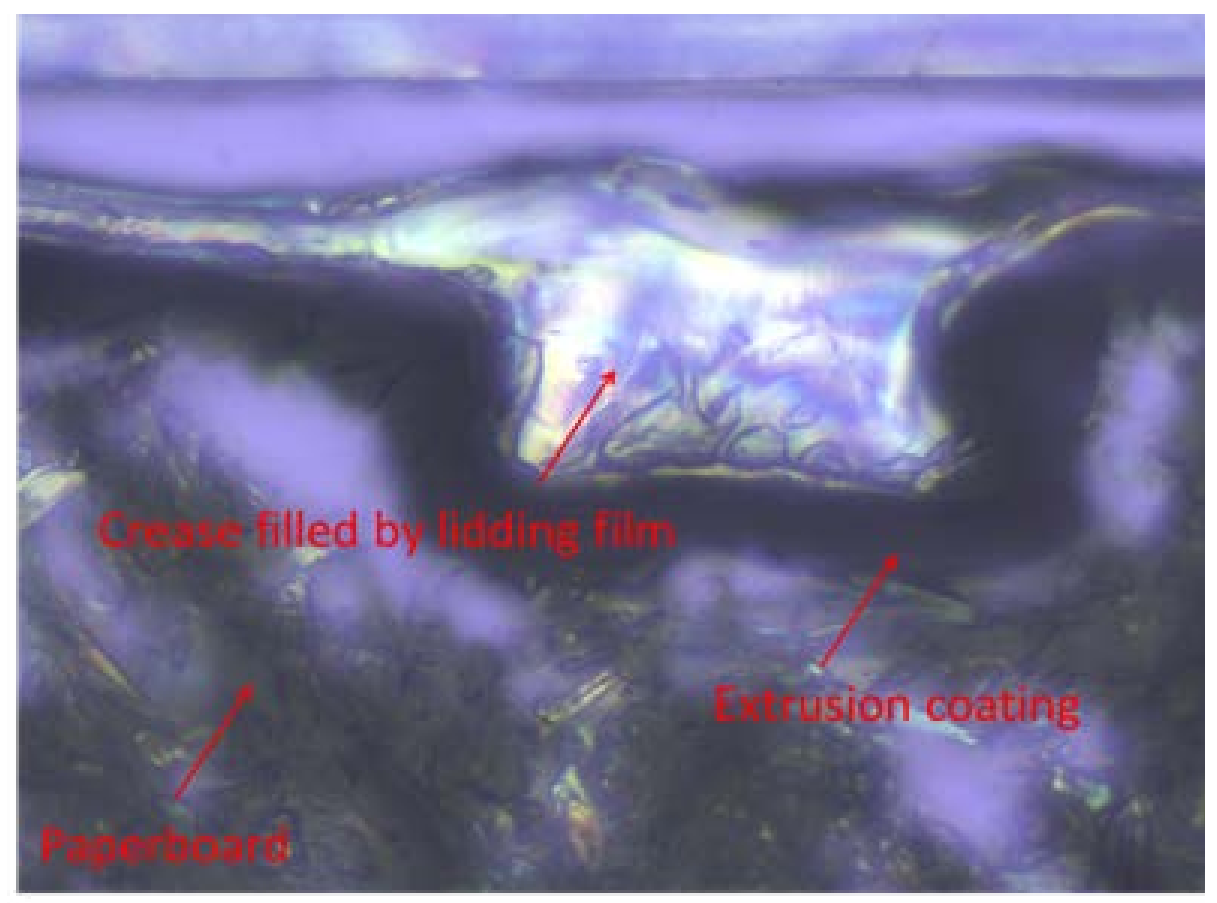

Figure 10. A microscopic image of a tight seal taken with a polarized light microscope 


\subsection{OPTICAL LIGHT MICROSCOPY}

The images (Figures 8 and 9) taken with an optical light microscope show clearly the structure of the different material layers and the formation of the crease. Figure 8 shows a tight seal in which the lidding plastic is properly bonded to the extrusion coating.

Figure 9 shows a leaking seal which has been detected by the coloring solution. The leak spot is easy to spot and investigate the cause of the leak when the coloring solution is visible in the images.

\subsection{POLARIZED LIGHT MICROSCOPY}

Polarized light microscopy shows clearly the different layers in materials. A sample of an image is in Figure 10. The different layers are recognizable but may be harder to understand than the pictures taken with a white light microscope.

\section{CONCLUSIONS}

Casting of the samples in an acrylic resin and light microscope imaging was found to be the most suitable method for this kind of analysis. The formation of creases, lidding material and leaks are easy to recognize from the images. Light microscopy is also the fastest and most affordable solution of when general material behavior is studied, as it also allows wider sample areas in a single sample, when compared to for example micro tomography.

All tested systems can be used in the leak analysis, but micro tomography, polarized light microscopy and SEM require very precise sample preparation when an individual crease indicated by coloring solution is studied. Light microscopy is also the only method that allows visual confirmation of leaks by showing the discoloration caused by the coloring solution. This is an important feature because leaks under the surface of the tray's rim area are not always visible in visual inspection. These small leaks, which can cause the modified atmosphere to be compromised, can be detected only in the microscopic images.

The use of microscopic imaging in the analysis of paperboard trays enables deeper understanding of material behavior of polymer coated paperboard in the press-forming process. This kind of information is crucial when new applications for environmentally friendly fiberbased packaging solutions are desired. Structural analysis of a paperboard tray can be done with all of the tested methods. However, when large amounts of samples are to be studied, optical light microscopy is the most affordable and efficient method. In addition, if leak detection by coloring solution and understanding of leak mechanics are to be studied, optical light microscopy is the only practical solution.

\section{REFERENCES}

[1] M. Hauptmann and J. Majschak, New Quality Level of Packaging Components from Paperboard through Technology Improvement in 3D Forming. Packaging Technology and Science, 24(7), 2011.

[2] A. Vishtal and E. Retulainen, Deepdrawing of paper and paperboard: the role of material properties. Bioresources, 7(3), 2012, pp. 4424-4450.

[3] P. Tanninen, H. Lindell, E. Saukkonen and K. Backfolk, Thermal and mechanical durability of starch-based dual polymer coatings in the press forming of paperboard. Packaging Technology and Science,27(5), 2014, pp. 353-363. 
[4] M. Hauptmann, S. Ehlert and J. Majschak, The Effect of Concave Base Shape Elements on the Three Dimensional Forming Process of Advanced Paperboard Structures. Packaging Technology and Science, 2014.

[5] V. Leminen, P. Tanninen, P. Mäkelä and J.Varis, Combined effect of paperboard thickness and mould clearance in the press forming process. Bioresources, 8(4), 2013, pp. 5701.

[6] X. Zeng, A. Vishtal, E. Retulainen, E. Sivonen and $\mathrm{S}$. Fu, The elongation potential of paper - How should fibres be deformed to make paper extensible? Bioresources, 8(1), 2013, pp. 472-486.

[7] V. Leminen, M. Kainusalmi, P. Tanninen and M. Lohtander, Effect of Sealing Temperature to Required Sealing Time in Heat Sealing Process of a Paperboard Tray. Journal of Applied Packaging Research, 6(2), 2012, pp. 67-78.

[8] M. Hauptmann, A. Schult, R. Zelm, T. Gailat, A. Lenske and J. Majschak and H. Grosmann, Gastight Paperboard Package, Professional Papermaking 1/2013, pp. 48-51.

[9] HJ. Yeh , Technical evaluation - methods for sealing paper foil aseptic food packages. TAPPI Journal 80, 1997, pp. 197-203.

[10] Stora Enso, [Homepage of Stora Enso], [Online] 2010. (Accessed 5 November 2014). [LINK]

[11] V. Kunnari, P. Jetsu and E. Retulainen, Formable paper for new packaging applications, 23rd symposium in international assosiation of packaging research institutes, IAPRI, 2007.
[12] Struers, [Homepage of Struers], [Online] 2008. (Accessed: 5 November 2014). [LINK]

[13] ILPRA [Online]. [LINK] (Accessed November 12014 ).

[14] CEN, European standard EN 13676 Polymer coated paper and board intended for food contact - Detection of pinholes. 2001

[15] R. Egerton. Physical Principles of Electron Microscopy: An Introduction to TEM, SEM, and AEM. Springer Science+Business Media, Inc., Boston MA, 2005.

[16] M. Hermand and T. Gabor. Fundamentals of Computerized Tomography Image Reconstruction from Projections. 2nd edn. Academic Press, 1980.

[17] D. Murphy and M. Davidson, Fundamentals of Light Microscopy and Electronic Imaging, . 2nd edn. Wiley, 2012.

[18] K. Randell, R. Ahvenainen, K LatvaKala, E. Hurme, T. Mattila-Sandholm, L. Hyvönen, Modified Atmosphere-packed Marinated Chicken Breast and Rainbow Trout Quality as Affected by Package Leakage, Journal of Food Science, 1995

[19] ASTM F1929-12, Standard Test Method for Detecting Seal Leaks in Porous Medical Packaging by Dye Penetration, ASTM International, West Conshohocken, PA, 2012, [LINK] [20] ASTM F3039-13, Standard Test Method for Detecting Leaks in Nonporous Packaging or Flexible Barrier Materials by Dye Penetration, ASTM International, West Conshohocken, PA, 2013,[LINK] 
[21] Witt, [Homepage of Witt], Online 2014.

[LINK] (Accessed 10 December 2014)

[22] ASTM F2714-08(2013), Standard

Test Method for Oxygen Headspace

Analysis of Packages Using Fluorescent

Decay, ASTM International, West

Conshohocken, PA, 2013, [LINK] 